\title{
Close Friendships and Mental Health of Korean American Adolescents: The Moderating Effect of Personality
}

\author{
Minjeong Kim¹, Jyu-Lin Chen ${ }^{2}$, Susan Kools ${ }^{3}$, Sandra Weiss ${ }^{4}$ \\ ${ }^{1}$ School of Nursing, San Diego State University, San Diego, USA \\ ${ }^{2}$ Department of Family Health Care Nursing, University of California, San Francisco, USA \\ ${ }^{3}$ Department of Family, Community and Mental Health Systems, University of Virginia, Charlottesville, USA \\ ${ }^{4}$ Department of Community Health Systems, University of California, San Francisco, USA \\ Email: minjeong.kim@sdsu.edu
}

How to cite this paper: Kim, M., Chen, J.-L., Kools, S., \& Weiss, S. (2018). Close Friendships and Mental Health of Korean American Adolescents: The Moderating Effect of Personality. Psychology, 9, 101-113. https://doi.org/10.4236/psych.2018.91007

Received: November 16, 2017

Accepted: January 14, 2018

Published: January 17, 2018

Copyright $\odot 2018$ by authors and Scientific Research Publishing Inc. This work is licensed under the Creative Commons Attribution International License (CC BY 4.0).

http://creativecommons.org/licenses/by/4.0/

\begin{abstract}
During adolescence, the youth increasingly rely on peers for intimacy and support. Since traditional Korean values emphasize the centrality of the family, this shift in emotional attachment may be especially challenging for Korean American youth. However, it is not known whether adolescents who lack a supportive close friendship may be at greater risk for mental health problems. The aims of this study were to determine whether the quality of the adolescents' closest friendship is associated with the mental health of Korean American adolescents, and whether specific personality traits of the youth may moderate any association between the quality of their friendships and their mental health problems. This cross-sectional study included 138 Korean American adolescents from community settings in California. A demographic questionnaire, the Relationship Quality Questionnaire, the NEO Five-Factor Inventory-3, and the Youth Self Report were completed by adolescents. Hierarchical regression analyses were used to examine the aims. Quality of the closest friendship was not a significant predictor of mental health problems for youth in general. However, the personality trait of agreeableness did predict better mental health. Agreeableness also showed a moderating effect, indicating that for youth who had less agreeable, more antagonistic personalities, a high quality relationship with their best friend was associated with fewer mental health problems. Longer residence in the U.S. was also related to better mental health. Findings suggest the need for early identification of youth who have poor relationships with close friends or a more antagonistic personality. It may be especially important to provide supportive mental health interventions for Korean American adolescents with these combined risks.
\end{abstract}




\section{Keywords}

Close Friendship, Korean American Adolescents, Mental Health, Personality

\section{Introduction}

Adolescents undergo a shift in their social affiliations from family to peers, becoming less emotionally dependent on their parents and building closer relationships with their friends. During this transition, the adolescent increasingly relies on peers for intimacy and social support and less on parents (Moretti \& Peled, 2004). Close friends become significant attachment figures who can represent a secure base for the youth as they manage the emotional stress and challenges of adolescence (Meurling, Ray, \& LoBello, 1999). Research has shown that peer relationship qualities are more strongly associated with adolescent attachment security than are parental relationship qualities, even during early and mid-adolescence (Allen \& Miga, 2010). Yet the quality of an adolescent's friends can vary, either serving as a positive source of emotional support and caring or contributing to fears of rejection and psychological insecurity. Substantial evidence has accumulated to show that unreliable or insensitive attachment figures can reduce resilience in coping with stressful life events and contribute to mental health problems (Mikulincer, Shaver, \& Berant, 2013). As key attachment figures during adolescence, close friends may have a major impact on the adolescent's mental health.

The influence of close friendships is of particular interest for Asian adolescents, including youth who are Korean American. Asian cultural values place a strong emphasis on connectedness to the family so the developmental shift in emotional attachment from parents to peers may be especially challenging for these youth (Yeh, 2003). Yet problems in achieving this developmental task could affect the quality of their peer relationships and have significant implications for their mental health (Johnson, et al., 2009; Pugh \& Hart, 1999). Only one study has examined the association between close peer relationships and the mental health of Korean American adolescents. Cho \& Bae (2005) found that a poor relationship with one's friends was significantly associated with more internalizing problems (i.e. depression, anxiety, withdrawal) among Korean American adolescents. This study suggested that poor quality in the close friendships of Korean American adolescents could result in feelings of isolation or rejection that contribute to greater risk for mental health problems.

In support of the above research, many studies have shown a positive peer relationship as one of the important factor of mental health problems in diverse ethnic adolescents. Chester, Jones, Zalot, and Sterrett (2007) found that African American youth who had better quality in their peer relationships had lower levels of depressive symptoms, less aggression, and fewer delinquent behaviors. McDonald, Bowker, Rubin, Laursen, and Duchene (2010) found that a supportive 
relationship with their same-sex best friend significantly predicted lower social anxiety in a group of ethnically diverse American adolescents, whereas, conflict with close friends significantly predicted higher levels of depression in a large sample of Canadian adolescents (Bosacki, Dane, \& Marini, 2007). A few longitudinal studies have also found that a decline in the quality of peer relationships was a significant factor in the development of depressive symptoms (Mendle, Harden, Brooks-Gunn, \& Graber, 2012), but it did not affect delinquent behaviors (Selfhout, Branje, \& Meeus, 2008). Overall, these studies suggest that more positive, supportive peer relationships are an important protective factor for an adolescent's mental health.

However, it is not known whether the quality of close friendships may be more or less important for the mental health of youth with certain personality traits. Personality traits are the unique and relatively stable characteristics of an individual's behavior, thought, and emotions. These traits can determine an individual's need for relationships or the value they place on close relationships. In a seminal study, Asendorpf and Wilpers (1998) found that extraversion, agreeableness and conscientiousness were associated with more positive, supportive close relationships. Lopes, Salovey, and Straus (2003) found that college students who were extraverted were more satisfied with their relationships while students with the trait of neuroticism (i.e. emotionally sensitive and moody) were less satisfied. King and Terrance (2006) reported that college students who had passive-aggressive, self-defeating, and borderline personality traits tended to view their closest friendship in more negative ways, suggesting poorer friendship quality. Lastly, Lincoln (2008) examined the mediating role of social support from relatives and friends in the relationship between personality traits and psychological distress. Investigators found that social support mediated the influence of personality traits on psychological distress differently for individuals with traits of extraversion versus neuroticism. Although none of these studies has addressed how personality traits may moderate the effect of close relationships on mental health of adolescents, research to date does implicate differences in the potential relationships of individuals who possess varied traits. It is possible that these traits may moderate the influence of close friendships on adolescents' mental health.

\section{Research Aims}

The purpose of this study was to advance knowledge regarding the influence of close friendships on the mental health of Korean American adolescents. An additional goal was to better understand whether any effect of close friendships on mental health might differ based on personality traits of the adolescents. The specific aims were 1) to determine whether the quality of the adolescents' closest friendship was associated with the mental health of Korean American adolescents, and 2) to determine whether specific personality traits would moderate any association between the quality of their closest friendship and mental health 
problems of these youths.

\section{Methods}

\subsection{Participants and Setting}

The sample for the current study included 138 adolescents. Participants were recruited from various Korean communities in California (Korean churches, Korean language schools, websites for the Korean community, Korean shopping malls and restaurants, and mental health centers for Asians and Pacific Islanders). Inclusion criteria were: 1) 10 - 19 years old, 2) is a Korean living in California, 3) able to communicate in English or in Korean, and 4) able to understand the purpose of this study.

\subsection{Procedure}

Approval was obtained from the Committee on Human Research (CHR) of the University of California-San Francisco for all aspects of this study. A packet of study materials including an informed written consent and self-report measures was sent to those who were interested in this study. Completed materials were returned back to the researcher. Participants received a $\$ 5$ gift card for participation. Follow-up e-mail or letters occurred when necessary to send reminder e-mail or to gather missing information. If the participant received above the clinical range scores on mental health problems, the researcher discussed the findings with the adolescent and parent or legal guardian and gave them a list of mental health resources. This study was conducted between January 2013 and December 2014.

\subsection{Measures}

\subsubsection{Demographic Variables}

Gender, age, length of residence in the U.S., parent education, and adequacy of family income were assessed. Parent education was assessed for each parent on a 4-point scale ranging from high school diploma or below (coded as 1) to graduate school or higher (coded as 4). Family income was assessed on the degree of adequacy of family income to meet their family's needs ranging from not enough money for food and place to live (coded as 1) to more money than we need (coded as 4).

\subsubsection{Close Friendship Quality}

Close friendship quality was assessed using the 21-item Relationship Quality Questionnaire (RQQ) (Meurling et al., 1999), a modified version of the Friendship Quality Questionnaire (FQQ) developed by Parker and Asher (1993). Participants indicated how true certain characteristics were about their relationship with their best friend (e.g., the friend makes them feel good about their ideas, gives them advice when figuring things out, makes them feel important and special, they tell each other their problems, and they get over arguments quickly). 
Response options were a 5-point Likert scale, with higher scores indicating better quality of their relationship with the close friend, suggesting that the friend serves as a greater source of emotional support and psychological security. The RQQ has not been used extensively with Asian American adolescents. However, it has good reliability ranging from .84 to .89 for the Cronbach's alpha and established a factor structure with seven domains (Meurling et al., 1999). In this study, the scale demonstrated good internal consistency $(\alpha=.86)$.

\subsubsection{Personality Traits}

Personality traits were measured using the NEO Five-Factor Inventory-3 (NEO-FFI-3) that is widely used to assess the following five personality traits: Neuroticism (N; emotional instability, distress in response to stressors), Extraversion (E; sociability, energy, positive emotionality), Openness to Experience (O; appreciation of personal emotion, curiosity, independent judgment), Agreeableness (A; trustfulness, altruism, cooperativeness), and Conscientiousness ( $\mathrm{C}$; goal directed, self-control, organization) (McCrae \& Costa, 2007). All five traits scores were used in this study. Each trait contains 12 items with the 4-point Likert scale. The NEO-FFI-3 has been used extensively in research on personality traits, and the scale demonstrated acceptable to good internal consistency (ranged from $\alpha=.72$ for Agreeableness to $\alpha=.83$ for Conscientiousness) and the five-factor structure was identified in the original testing of the scale with a sample of 500 adolescents including 8\% Asian Pacific Islander (API) adolescents (McCrae \& Costa, 2007). In this study, Cronbach's alphas were .80 for Neuroticism, .75 for Extraversion, .75 for Openness, .72 for Agreeableness, and .81 for Conscientiousness.

\subsubsection{Mental Health Problems}

Mental health problems were measured using the Youth Self Report (YSR), a self-reported questionnaire that is widely used to assess adolescents' problematic feelings, thoughts, and behaviors during the past 6 months (Achenbach \& Rescorla, 2001). The YSR has eight empirically-based syndrome scales: Anxious/ Depressed, Withdrawn/Depressed, Somatic Complaints, Social Problems, Thought Problems, Attention Problems, Rule-Breaking Behavior, and Aggressive Behavior. Because our main interest was in considering the moderating effect of personality with the relationship between close friendship quality and overall mental health problems, the Total Problems score was used for our analyses. The YSR consists of 112 items using a 3-point Likert scale, with higher scores indicating more mental health problems. The YSR has demonstrated reliability and validity across various populations including Korea as well as Western countries (Ivanova et al., 2007; Rescorla et al., 2007). Excellent Cronbach's alpha scores for the Total Problems scale $(\alpha=.93-.95)$ have been established (Achenbach \& Rescorla, 2001; Ebesutani et al., 2011; Ivanova et al., 2007; Rescorla et al., 2007). In this study, Cronbach's alpha was .94 for the Total Problems scale. 


\subsection{Data Analysis}

SPSS version 22 was used to compute all statistical procedures for this study. As preliminary analyses, descriptive statistics including frequency and percent or means and standard deviations ( $S D S$ ) were used for all key variables. Bivariate correlations for continuous variables and t-tests for categorical variables were also computed. The distribution for adequacy of family income and parent education warranted creation of dichotomous groupings for these categorical variables. In order to examine specific aims of this study, hierarchical linear regression analyses were used. To examine Aim 1, length of residence in the U.S. which is the only significant demographic variable, was entered in the regression analysis at the first step to control for its effect. In the second step, the RQQ score for quality of the close friendship was entered. To examine Aim 2, five separate hierarchical regressions were computed initially to examine the unique contribution of each personality trait and its interaction to the quality of the close friendship. In these models, length of residence in the U.S. was entered at the first step, the score for quality of the friendship and one of the personality traits were entered at the second step, and the interaction between friendship quality and the trait was entered at the third step. Significance level was set at an alpha level of .05 in all analyses.

\section{Results}

The sample for the current study included 138 Korean American adolescents (mean age $=14.4, S D=2.1,59 \%$ female). The average length of residence in the U.S. was 12.4 years (ranges from less than 1 to $18, S D=4.1$ ). Approximately $70 \%$ of parents completed either college or graduate studies. Most participants reported that "their family had enough money but no extra," or "they had more money than they need."

Table 1 shows bivariate correlations for all key variables. Length of residence in the U.S. had a high correlation with age and a low but significant correlation

Table 1. Means and correlations for age, length of residence in the U.S., close friendship quality, personality traits, and total mental health problems.

\begin{tabular}{|c|c|c|c|c|c|c|c|c|c|c|}
\hline Variable & $M(S D)$ & 1 & 2 & 3 & 4 & 5 & 6 & 7 & 8 & 9 \\
\hline 1. Age & $14.43(2.09)$ & - & $.50^{* *}$ & -.14 & $.19^{*}$ & -.11 & .11 & -.14 & .05 & .14 \\
\hline 2. Length of residence in the U.S. & $12.36(4.14)$ & & - & .14 & $.19^{*}$ & .02 & .07 & .10 & .04 & $.19^{*}$ \\
\hline 3. Friendship quality & $73.38(14.84)$ & & & - & .01 & $.22^{*}$ & -.06 & $.19^{*}$ & $.29^{* *}$ & -.08 \\
\hline 4. Neuroticism & $25.62(7.52)$ & & & & - & -.09 & .12 & $-.21^{*}$ & -.16 & $.68^{\star *}$ \\
\hline 5. Extraversion & $30.91(5.88)$ & & & & & - & $.19^{*}$ & .07 & .15 & -.08 \\
\hline 6. Openness & $28.53(6.37)$ & & & & & & - & .14 & .04 & .14 \\
\hline 7. Agreeableness & $31.55(5.91)$ & & & & & & & - & .17 & $-.30^{* *}$ \\
\hline 8. Conscientiousness & $29.10(6.49)$ & & & & & & & & - & -.12 \\
\hline 9. Total problems & $45.30(23.65)$ & & & & & & & & & - \\
\hline
\end{tabular}

Note: ${ }^{*} p<.05,{ }^{* *} p<.01$. 
with mental health problems. The personality trait of neuroticism had a high positive correlation with mental health problems. The personality trait of agreeableness had a negative moderate correlation with mental health problems. Age and the personality traits of extraversion, openness, and conscientiousness were not significantly correlated with mental health problems. In addition, no significant differences in mental health problems were present between gender, among father and mother's educational level, or family income. Quality of the adolescents' closest friendship was associated positively with 3 personality traits: extraversion, agreeableness and conscientiousness but it was not associated with the adolescents' mental health problems.

Table 2 shows findings for Aim 1. In the final model for this regression (step 2 ), length of residence in the U.S. had a significant relationship to mental health problems ( $\beta=.22, p<.05$ ), explaining $4.1 \%$ of the variance in mental health problems. Quality of the closest friendship was not a significant predictor $(\beta=$ $-.11, p=.21)$. The total model explained $5.3 \%$ of the variance in mental health problems $(F(2,123)=3.44, p<.05)$.

Among the five separate hierarchical regression models, only 1 personality trait, agreeableness, showed a significant interaction with quality of the closest friendship. Table 3 shows the findings of this regression. In the final model for this regression (step 3), length of residence in the U.S. was a significant predictor of the mental health problems ( $\beta=.25, p<.01$ ), explaining $4.6 \%$ of the variance in mental health problems. Both friendship quality $(\beta=-1.09, p<.01)$ and the agreeableness trait $(\beta=-1.33, p<.01)$ were significant predictors when their direct effects were examined. Together, friendship quality and agreeableness explained an additional $9.5 \%$ of the variance in mental health problems ( $F$ change $=6.54, p<.01)$. Finally, the interaction between friendship quality and agreeableness accounted for an additional $4.6 \%$ of the variance in mental health problems ( $F$ change $=6.66, \beta=1.62, p<.05)$. In order to examine the interaction effect, correlations were computed between friendship quality and mental health problems for adolescents with low versus high agreeableness. Youth were split at the mean level of the trait of agreeableness to determine these groups and partial correlations were computed controlling for length of residence in the U.S.

Table 2. Hierarchical regression analysis for effects of demographics and close friendship quality on mental health problems.

\begin{tabular}{lccc}
\hline \multicolumn{1}{c}{ Variable } & $B$ & $S E B$ & $\beta$ \\
\hline Step 1 & & & $.20^{\star}$ \\
$\quad$ Length of residence in the U.S. & 1.21 & .53 & $.22^{\star}$ \\
Step 2 & & & .53 \\
$\quad$ Length of residence in the U.S. & 1.30 & .15 & -.11 \\
Close friendship quality & -.18 &
\end{tabular}

Note: $R^{2}=.04$ for Step $1 ; R^{2}$ change $=.01$ for Step $2(p=.21) .{ }^{*} p<.05$. 
Table 3. Effects of close friendship quality, agreeableness, and their interaction on mental health problems.

\begin{tabular}{lccc}
\hline \multicolumn{1}{c}{ Variable } & $B$ & $S E B$ & $\beta$ \\
\hline Step 1 & & & $.22^{*}$ \\
$\quad$ Length of residence in the U.S. & 1.28 & .53 & \\
Step 2 & & & $.25^{* *}$ \\
$\quad$ Length of residence in the U.S. & 1.51 & .52 & -.06 \\
Close friendship quality & -.10 & .14 & $-2.94^{* *}$ \\
Agreeableness & -1.19 & .35 & $.25^{* *}$ \\
Step3 & & & $-1.09^{* *}$ \\
Length of residence in the U.S. & 1.52 & .50 & $-1.33^{* *}$ \\
Close friendship quality & -1.78 & .67 & $1.62^{*}$ \\
Agreeableness & -5.37 & 1.66 & .02 \\
Close friendship quality $\times$ Agreeableness & .05 & & \\
\hline
\end{tabular}

Note: $R^{2}=.05$ for Step $1 ; R^{2}$ change $=.10$ for Step $2(p<.01) ; R^{2}$ change $=.05$ for Step $3(p<.05) .{ }^{*} p<.05$, ${ }^{* *} p<.01$.

Correlations indicated that for youth who were low in agreeableness, better quality of the relationship with their best friend was associated with fewer mental health problems $(r=-.33, p<.05)$. However, for youth who were high in agreeableness, there was no significant relationship between friendship quality and mental health problems $(r=.11, p=.36)$. The overall model was significant, with all variables explaining $18.8 \%$ of the variance in mental health problems of the Korean American adolescents $(F(4,117)=6.76, p<.001)$.

\section{Discussion}

This study examined the association between the quality of Korean American adolescents' relationships with their closest friends and their mental health problems as well as the ways in which their personality traits might moderate any effect of the close friendship on their mental health. Findings related to Aim 1 indicate that quality of the friendship did not predict mental health problems for these youths overall, but length of residence in the U.S. did predict more problems. However, one personality trait (agreeableness) did moderate the relationship between friendship quality and adolescent mental health, indicating the importance of this relationship for a specific group of youth (Aim 2). Adolescents who had less agreeable personalities were at greater risk for mental health problems by virtue of their personality trait. However, the quality of the relationship with their best friend served as a protective factor, reducing their mental health risk. In contrast, the quality of their closest friendship did not influence the mental health problems of adolescents who had more agreeable personalities in any way. For this group, their trait of agreeableness itself reduced their risk for mental health problems. The four other personality traits studied did not demonstrate a significant moderating effect between close friendships and 
mental health.

\subsection{Friendship Quality and Mental Health}

Our findings regarding the lack of any influence of close peer relationships on mental health problems for our entire sample are in conflict with results from a number of studies that showed a significant relationship between poor quality of peer relationships and depression, social anxiety, and internalizing problems (Bosacki et al., 2007; Chester et al., 2007; Cho \& Bae, 2005; McDonald et al., 2010; Mendle et al., 2012). However, our findings are consistent with results from 2 studies showing that the quality of close friendships was not a significant factor in delinquency (Selfhout et al., 2008) or in the development of overall mental health problems (Okello, Nakimuli-Mpungu, Musisi, Broekaert, \& Derluyn, 2014). It is possible that the quality of close friendships plays a greater role in predicting internalizing problems such as depression and anxiety than for externalizing problems. Because we looked at the total mental health problems of the adolescents, this differential effect may have been missed.

\subsection{Agreeableness and Mental Health}

To our knowledge, our finding regarding the potential impact of agreeableness as a predictor and moderator of Korean American adolescents' mental health has never been reported. However, there is a body of literature indicating that agreeableness is associated with greater psychological resilience in adolescents (Fayombo, 2010), better mental health outcomes among college students (Shirazi et al., 2012), and subjective well-being (Haslam et al., 2009). A longitudinal study found that 8 year old boys and girls who scored higher on agreeableness had fewer behavior problems and lower levels of substance abuse and depression 25 years later (Laursen et al., 2002). In contrast, individuals low on agreeableness are typically described as antagonistic, impulsive, and irritable, resulting in a greater vulnerability to social rejection (Bierman, 2003). Research indicates that adolescents who are rejected by their peers are more likely to be lonely, and to have lower self-esteem and more internalizing problems (Smetana, Campione-Barr, \& Metzger, 2006). For less agreeable individuals, having a close friend who can enhance their sense of belonging, provide emotional security or buffer their less socially acceptable behavior with others may be especially important for their ability to cope successfully and manage ongoing challenges in their lives. Adolescents who describe feeling better about the quality of their close friendships have shown greater feelings of belongingness and decreased loneliness in previous research (Chen, 2009). This type of supportive close relationship may be less important for the mental health of adolescents whose agreeable personality naturally increases their likelihood of being well-received by others and achieving social success.

These findings may have particular salience for Asian American adolescents who experience strong expectations within their culture to embrace Asian family values of interpersonal harmony, interdependence, and conformity to family and social norms (Greenfield et al., 2003; Kim et al., 2001). Korean American youth 
whose less agreeable personalities do not comply with these values may experience unique psychological conflicts that erode their mental health. Because of this increased vulnerability, emotional support and caring from a close friend may act as more essential mental health resource.

\subsection{Limitations and Future Research}

Limitations of the study include its cross-sectional design. The association between quality of close friendships and adolescent mental health may look different over time. Longitudinal studies are needed to determine whether the quality of close friendships measured early in life predict the development of mental health problems as a child develops. In addition, our measure of the quality of peer relationships only examined the adolescents' closest friendship. Measures that assess other peer relationships may improve the understanding of peer effects on mental health. For example, whether their best friend is a Korean American or an American may be one of the important factors associated with mental health, in that having a best friend with same race/ethnicity may provide their sense of belonging and emotional security, leading to better mental health, especially in Korean American adolescents who are expected to embrace collectivism. Because our measure of the quality of peer relationships has not been extensively studied in Korean American adolescents, it needs more psychometric testing among this population. Also, the use of a structured clinical interview that does not solely depend on self-report would strengthen the reliability of the assessment of adolescent mental health problems. Lastly, findings from our convenience sample may not be generalizable to the larger Korean American population in the U.S. or to other cultural groups, including other Asian American adolescents.

Findings of this study have a number of implications for future research. Emotional support and shared intimacy with a close friend may influence some mental health problems more than others. Therefore, it will be important to examine how the quality of a close friendship is related to specific problems, especially whether it has a greater impact on internalizing behavior problems such as depression and anxiety or externalizing behavior problems such as aggression and rule-breaking behaviors. Research with a larger sample is also needed to more carefully examine the moderating effects of agreeableness. A larger sample size will help to find potential significant moderating effects of other personality traits as well. Because length of residence in the U.S. predicted more mental health problems for the youth, future research should examine in detail how it may be influencing these problems.

\subsection{Clinical Implications}

Findings have implications for identification of Korean American youth at greater risk for mental health problems, specifically adolescents who show evidence of more antagonistic and irritable approaches with their peers or families 
and who have few close friends whom they can turn to for support and caring. Although this study did not find a significant relationship between the quality of an adolescent's closest friendship and mental health problems overall, friendship quality was a protective factor for the mental health of adolescents who had less agreeable personalities. Education about relationships among overall mental health problems, close friendships, and personality traits can be provided for health care professionals. Assessment of these risk factors can be included in pediatric clinics or in counseling service programs. Also, as a part of community-based prevention strategies, mental health awareness education based on findings from this study can be provided targeted for family members, school teachers, and community leaders, such as pastors and youth community program leaders. Support groups may be an effective approach to working with these youths to improve their mental health. For example, development and evaluation of mood/anxiety mobile tracker program utilizing peer support may be one of the innovative strategies, reflecting mobile generation and current trend of research and clinical interventions using mobile health and technology.

\section{Acknowledgements}

Minjeong Kim, $\mathrm{PhD}, \mathrm{RN}$ thanks to Michelle Lee, undergraduate research assistant in the School of Nursing, San Diego State University, USA, for her manuscript preparation and editing.

\section{References}

Achenbach, T. M., \& Rescorla, L. A. (2001). Manual for the ASEBA School-Age Forms and Profiles. Burlington, VT: University of Vermont Research Center for Children, Youth, \& Families.

Allen, J. P., \& Miga, E. M. (2010). Attachment in Adolescence: A Move to the Level of Emotion Regulation. Journal of Social and Personal Relationships, 27, 181-190. https://doi.org/10.1177/0265407509360898

Asendorpf, J. B., \& Wilpers, S. (1998). Personality Effects on Social Relationships. Journal of Personality and Social Psychology, 74, 1531-1544. https://doi.org/10.1037/0022-3514.74.6.1531

Bierman, K. (2003). Peer Rejection: Development Processes and Intervention Strategies. New York: Guilford Press.

Bosacki, S., Dane, A., \& Marini, Z. (2007). Peer Relationships and Internalizing Problems in Adolescents: Mediating Role of Self-Esteem. Emotional \& Behavioural Difficulties, 12, 261-282. https://doi.org/10.1080/13632750701664293

Chen, W.-C. (2009). Adolescent Interpersonal Relationship Quantity and Quality, Belongingness, and Loneliness. Archive of Guidance \& Counseling, 31, 17-37.

Chester, C., Jones, D. J., Zalot, A., \& Sterrett, E. (2007). The Psychosocial Adjustment of African American Youth from Single Mother Homes: The Relative Contribution of Parents and Peers. Journal of Clinical Child and Adolescent Psychology, 36, 356-366. https://doi.org/10.1080/15374410701444306

Cho, S., \& Bae, S.-W. (2005). Demography, Psychosocial Factors, and Emotional Problems of Korean American Adolescents. Adolescence, 40, 533-550. 
Ebesutani, C., Bernstein, A., Martinez, J. I., Chorpita, B. F., \& Weisz, J. R. (2011). The Youth Self Report: Applicability and Validity across Younger and Older Youths. Journal of Clinical Child and Adolescent Psychology, 40, 338-346. https://doi.org/10.1080/15374416.2011.546041

Fayombo, G. (2010). The Relationship between Personality Traits and Psychological Resilience among Caribbean Adolescents. International Journal of Psychological Studies, 2, 105-116. https://doi.org/10.5539/ijps.v2n2p105

Greenfield, P. M., Keller, H., Fuligni, A., \& Maynard, A. (2003). Cultural pathways through universal development. Annual Review of Psychology, 54, 461-490. https://doi.org/10.1146/annurev.psych.54.101601.145221

Haslam, N., Whelan, J., \& Bastian, B. (2009). Big Five Traits Mediate Associations between Values and Subjective Well-Being. Personality and Individual Differences, 46, 40-42. https://doi.org/10.1016/j.paid.2008.09.001

Ivanova, M. Y., Achenbach, T. M., Dumenci, L., Rescorla, L. A., Almqvist, F., Weintraub, S., Verhulst, F. C. et al. (2007). Testing the 8-Syndrome Structure of the Child Behavior Checklist in 30 Societies. Journal of Clinical Child and Adolescent Psychology, 36, 405-417. https://doi.org/10.1080/15374410701444363

Johnson, S. B., Blum, R. W., \& Giedd, J. N. (2009). Adolescent Maturity and the Brain: The Promise and Pitfalls of Neuroscience Research in Adolescent Health Policy. Journal of Adolescent Health, 45, 216-221. https://doi.org/10.1016/j.jadohealth.2009.05.016

Kim, B. S. K., Atkinson, D. R., \& Umemoto, D. (2001). Asian Cultural Values and the Counseling Process: Current Knowledge and Directions for Future Research. Counseling Psychologist, 29, 570-603. https://doi.org/10.1177/0011000001294006

King, A. R., \& Terrance, C. (2006). Relationships between Personality Disorder Attributes and Friendship Qualities among College Students. Journal of Social and Personal Relationships, 23, 5-20. https://doi.org/10.1177/0265407506058696

Laursen, B., Pulkkinen, L., \& Adams, R. (2002). The Antecedents and Correlates of Agreeableness in Adulthood. Developmental Psychology, 38, 591-603.

https://doi.org/10.1037/0012-1649.38.4.591

Lincoln, K. D. (2008). Personality, Negative Interactions, and Mental Health. Social Service Review, 82, 223-252. https://doi.org/10.1086/589462

Lopes, P. N., Salovey, P., \& Straus, R. (2003). Emotional Intelligence, Personality, and the Perceived Quality of Social Relationships. Personality and Individual Differences, 35, 641-658. https://doi.org/10.1016/S0191-8869(02)00242-8

McCrae, R. R., \& Costa, P. T. (2007). Brief Versions of the NEO-PI-3. Journal of Individual Differences, 28, 116-128. https://doi.org/10.1027/1614-0001.28.3.116

McDonald, K. L., Bowker, J. C., Rubin, K. H., Laursen, B., \& Duchene, M. S. (2010). Interactions between Rejection Sensitivity and Supportive Relationships in the Prediction of Adolescents' Internalizing Difficulties. Journal of Youth and Adolescence, 39, 563-574. https://doi.org/10.1007/s10964-010-9519-4

Mendle, J., Harden, K. P., Brooks-Gunn, J., \& Graber, J. A. (2012). Peer Relationships and Depressive Symptomatology in Boys at Puberty. Developmental Psychology, 48, 429-435. https://doi.org/10.1037/a0026425

Meurling, C.-J. N., Ray, G. E., \& LoBello, S. G. (1999). Children's Evaluations of Classroom Friend and Classroom Best Friend Relationships. Child Study Journal, 29, 79-96.

Mikulincer, M., Shaver, P. R., \& Berant, E. (2013). An Attachment Perspective on Therapeutic Processes and Outcomes. Journal of Personality, 81, 606-616.

https://doi.org/10.1111/j.1467-6494.2012.00806.x 
Moretti, M. M., \& Peled, M. (2004). Adolescent-Parent Attachment: Bonds That Support Healthy Development. Paediatrics and Child Health, 9, 551-555. https://doi.org/10.1093/pch/9.8.551

Okello, J., Nakimuli-Mpungu, E., Musisi, S., Broekaert, E., \& Derluyn, I. (2014). The Association between Attachment and Mental Health Symptoms among School-Going Adolescents in Northern Uganda: The Moderating Role of War-Related Trauma. PLoS One, 9, e88494. https://doi.org/10.1371/journal.pone.0088494

Parker, J. G., \& Asher, S. R. (1993). Friendship and Friendship Quality in Middle Childhood: Links with Peer Group Acceptance and Feelings of Loneliness and Social Dissatisfaction. Developmental Psychology, 29, 611-621. https://doi.org/10.1037/0012-1649.29.4.611

Pugh, M. J. V., \& Hart, D. (1999). Identity Development and Peer Group Participation. New Directions for Child and Adolescent Development, No. 84, 55-70. https://doi.org/10.1002/cd.23219998406

Rescorla, L. A., Achenbach, T. M., Ivanova, M. Y., Dumenci, L., Almqvist, F., Bilenberg, N., \& Verhulst, F. (2007). Behavioral and Emotional Problems Reported by Parents of Children Ages 6 to 16 in 31 Societies. Journal of Emotional and Behavioral Disorders, 15, 130-142. https://doi.org/10.1177/10634266070150030101

Selfhout, M. H. W., Branje, S. J. T., \& Meeus, W. H. J. (2008). The Development of Delinquency and Perceived Friendship Quality in Adolescent Best Friendship Dyads. Journal of Abnormal Child Psychology, 36, 471-485. https://doi.org/10.1007/s10802-007-9193-5

Shirazi, M., Khan, M. A., \& Ansari, F. A. (2012). Mental Health in Relation to Personality Characteristics among Professional and Nonprofessional Students. Journal of Arts, Science and Commerce, III, 8-15.

Smetana, J. G., Campione-Barr, N., \& Metzger, A. (2006). Adolescent Development in Interpersonal and Societal Contexts. Annual Review of Psychology, 57, 255-284. https://doi.org/10.1146/annurev.psych.57.102904.190124

Yeh, C. J. (2003). Age, Acculturation, Cultural Adjustment, and Mental Health Symptoms of Chinese, Korean, and Japanese Immigrant Youths. Cultural Diversity and Ethnic Minority Psychology, 9, 34-48. https://doi.org/10.1037/1099-9809.9.1.34 